Gut, 1986, 27, 680-685

\title{
Body composition in ileostomy patients with and without ileal resection
}

\author{
J C COOPER, A LAUGHLAND, E J GUNNING, L. BURKINSHAW, AND \\ N S WILLIAMS.
}

From the University Departments of Surgery, Medical Physics and Dietetics, The General Infirmary, Leeds

SUMMARY Body composition was measured in 24 patients who had previously undergone proctocolectomy and ileostomy. One group (control group) had undergone resection of only small amounts of terminal ileum (median $4 \mathrm{~cm}$ ), the other group of patients (resected group) had undergone resection of greater lengths of small bowel (median $54 \mathrm{~cm}$ ). These values of body composition were then compared with predicted values in normal subjects. Proctocolectomy and ileostomy without ileal resection did not significantly affect body weight, or the body contents of fat or water, but led to a reduction in total body nitrogen and total body potassium, suggesting a reduction in fat free mass. A modest resection of the terminal ileum undertaken during the course of proctocolectomy decreased body weight largely because of a reduction in body fat. None of the ileostomy patients was found to be dehydrated.

Proctocolectomy and the establishment of an ileostomy leads to increased fluid and electrolyte losses even when adaptation is complete, and such patients are susceptible to salt and water depletion. ${ }^{1}$ Should a resection of the terminal ileum accompany proctocolectomy impairment of the adaption process can occur resulting in even greater ileostomy outputs. $^{2}$ Even after a modest resection of the terminal ileum $(50-60 \mathrm{~cm})$ patients can suffer disproportionately high outputs of water and electrolytes. ${ }^{2-5}$ Recent evidence has also shown that such patients excrete increased amounts of fat and nitrogen ${ }^{6}$ compared with ileostomy patients who have not undergone a resection. Important clinical implications are thus apparent as continual loss of nutrients and electrolytes could lead to serious nutritional deficits. Surprisingly, however, there is little information regarding their nutritional state and in particular their body composition. Most studies of ileostomy patients have concentrated on the estimation of total body water and electrolytes ${ }^{7-9}$ using isotope dilution techniques, and have not measured the body contents of fat, nitrogen, and minerals. Furthermore, although one study measured body composition in ileostomy patients with the short bowel syndrome ${ }^{10}$ no studies are available

Address for correspondence: Professor N S Williams, MS. FRCS. Surgical Unit. The London Hospital. Whitechapel. London EI IBB. which have measured body composition after a modest resection of the terminal ileum. Because the latter is a frequent adjunct to the operation of proctocolectomy its effect upon the nutritional state of these patients has important clinical relevance.

The aims of the present study were, therefore, to measure the body composition of one group of ileostomy patients without ileal resection, and a second group who had undergone a modest ileal resection and then compare these values with predicted values in normal subjects.

\section{Methods}

PATIENTS

Twenty four patients with well established ileostomies agreed to take part in the study, the protocol having been approved by the Leeds Western District Ethics Committee. All the subjects had undergone proctocolectomy for ulcerative colitis apart from one patient who had suffered from Crohn's colitis. This patient's small bowel was radiologically normal at the time of the study.

Twelve patients had undergone only minimal resection of the ileum (control group: median $4 \mathrm{~cm}$ [range 2-10 cm]) and 12 patients had undergone resection of a greater length of ileum mainly for a failed ileal reservoir (resected group: $54 \mathrm{~cm}$ $[50-120 \mathrm{~cm}] ; p<0 \cdot 002)$. Subjects in the resected group 
Table 1 Clinical details of the two study groups

\begin{tabular}{|c|c|c|}
\hline & $\begin{array}{l}\text { Control group } \\
n=12\end{array}$ & $\begin{array}{l}\text { Resected group } \\
n=12\end{array}$ \\
\hline Age (years) mean \pm SD & $42 \cdot 4 \pm 13 \cdot 5$ & $42 \cdot 1 \pm 17 \cdot 2$ \\
\hline Sex M:F & $6: 6$ & $6: 6$ \\
\hline Height $(\mathrm{cm})$ mean $\pm S D$ & $171 \cdot 0 \pm 9 \cdot 5$ & $172 \cdot() \pm 12 \cdot()$ \\
\hline $\begin{array}{l}\text { Time interval between } \\
\text { op \& study (years) } \\
\text { median (range) }\end{array}$ & $5 \cdot 8(1 \cdot 5-15)$ & $2 \cdot 5(1 \cdot 5-16)$ \\
\hline
\end{tabular}

were individually matched with control subjects for age, sex and height (Table 1). The median time interval between operation and the study in the control group $(5 \cdot 8$ years [range $1.5-15$ years]) was greater, but not significantly so, than that of the resected group ( $2 \cdot 5$ years [ $1.5-16$ years]; p-NS). Six of the patients (five resected, one control) were taking antidiarrhoeal medication in an attempt to reduce ileostomy output. Two patients were taking nonsteroidal anti-inflammatory drugs for arthritis, and a further two bronchodilators for asthma. All patients were fit, and many were in full-time employment.

On the day of the study each patient had their weight and height recorded. A sample of venous blood was taken for estimation of haemoglobin concentration and plasma concentration of urea, electrolytes, calcium, phosphate, total protein and albumin. Total body water was calculated from the dilution in the body of $100 \mu \mathrm{Ci}$ of tritiated water given intravenously. A plasma sample was taken at three and five hours after injection and duplicate aliquots of the plasma samples and appropriate standards were added to a NE260 (Nuclear Enterprises (GB) Ltd) scintillator and measured on a liquid scintillation counter. Skin fold thicknesses were measured at the biceps, triceps, subscapular, and suprailiac sites using Holtain skin fold calipers from which body density was calculated using the regression equations of Durnin and Womersley. ${ }^{11}$ From this estimate total body fat was then calculated using Siri's equation. ${ }^{12}$

Using neutron activation analysis ${ }^{13} 14$ measurements were made of the body contents of nitrogen, sodium, chlorine, phosphorus, and calcium, and the content of potassium by virtue of its natural radioactive constituent ${ }^{40} \mathrm{~K} .{ }^{15}$ Each patient, lying supine, was irradiated bilaterally with a horizontal beam of $14 \mathrm{Mev}$ neutrons to a dose equivalent of $5 \mathrm{mSv}$. The patient was then transferred to a whole body radiation counter where the radioactivity induced in the body by the neutrons was measured for 30 minutes, and the resulting gamma ray spectrum was analysed to give the masses of the six elements. The procedure was approved by the Administration of
Radioactive Substances Advisory Committee of the Department of Health and Social Security.

In the week immediately after the study 24 hour ileostomy outputs were recorded on a normal diet, and the patients kept a seven day dietary diary, charting in detail everything they ate and drank during that period. This diary was then analysed by an experienced dietitian and with the aid of a computer the mean daily quantity of food eaten was calculated.

The values of body weight, total body fat, water, nitrogen, and potassium of the patients in the study were compared with predicted values for normal subjects matched for age, sex, and height. The predicted values were determined from regression equations based upon previous measurements of 91 normal volunteer subjects of similar ages (21-68 years) and height (150-188 cm), and both sexes (29 women:62 men) in our laboratory. ${ }^{16}$ The volunteers were measured as described above except that a lower dose of neutrons was administered and total body water was calculated by subtracting total body fat, total body protein (total body nitrogen $\times 6 \cdot 25$ ), and total body minerals from body weight (total body water diff). Hence in comparing the values for total body water in the patients with those predicted the values estimated by difference were used.

\section{STATISTICAL ANALYSIS}

The Mann-Whitney $U$ test for non-parametric data ${ }^{17}$ was used to compare the differences between the groups with regard to the length of ileal resection, the time since surgery, and the 24 hour ileostomy output. All other data were compared using Student's $t$ test for parametric data. ${ }^{17}$ Degrees of significance are all two-tailed values.

\section{Results}

\section{ILEOSTOMY OUTPUT}

The 24 hour ileostomy output was significantly greater in patients who had undergone ileal resection (median $900 \mathrm{~g}$ [range 609-5790 g]) compared with patients who had undergone no ileal resection (570 g [396-894 g]; $\mathrm{p}<0.002)$.

HAEMATOlOgical INDices (Table 2)

Values of all the haematological indices measured were similar for patients in the resected group compared with patients in the control group, and all values were within the normal range of our laboratory.

DIETARY INTAKE (Table 3 )

Mean daily intake of fluid, major foodstuffs and minerals were consistently $15-20 \%$ greater in the 
Table 2 Haematological and biochemical indices

\begin{tabular}{llll}
\hline & $\begin{array}{l}\text { Control } \\
\text { group }\end{array}$ & $\begin{array}{l}\text { Resected } \\
\text { group }\end{array}$ & $\begin{array}{l}\text { Normal for } \\
\text { laboratory }\end{array}$ \\
\hline $\mathrm{Hb} .(\mathrm{g} / \mathrm{dl})$ & $13 \cdot 7 \pm 1 \cdot 1$ & $13 \cdot 7 \pm 1 \cdot 1$ & $12-17$ \\
$\begin{array}{l}\text { Plasma Na+ } \\
(\mathrm{mmol} / \mathrm{l})\end{array}$ & $139 \pm 1 \cdot 7$ & $139 \pm 2 \cdot 8$ & $135-145$ \\
$\mathrm{~K}+(\mathrm{mmol} / \mathrm{l})$ & $3 \cdot 9 \pm 0 \cdot 3$ & $3 \cdot 9 \pm 0 \cdot 3$ & $3 \cdot 6-5 \cdot 0$ \\
$\mathrm{Cl}-(\mathrm{mmol} / \mathrm{l})$ & $101 \pm 1 \cdot 2$ & $100 \pm 3 \cdot 2$ & $98-107$ \\
$\mathrm{Ca} 2+(\mathrm{mmol} / \mathrm{l})$ & $2 \cdot 4 \pm 0 \cdot 1$ & $2 \cdot 3 \pm 0 \cdot 1$ & $2 \cdot 25-2 \cdot 60$ \\
$\begin{array}{l}\text { Urea }(\mathrm{mmol} / \mathrm{l}) \\
\text { Serum albumin } \\
(\mathrm{g} / \mathrm{l})\end{array}$ & $4 \cdot 5 \pm 1 \cdot 3$ & $4 \cdot 6 \pm 1 \cdot 0$ & $2 \cdot 5-7 \cdot 1$ \\
$\begin{array}{c}\text { Serum protein } \\
(\mathrm{g} / \mathrm{l})\end{array}$ & $45 \pm 3$ & $44 \pm 3$ & $37-49$ \\
\hline
\end{tabular}

Values mean $\pm \mathrm{SD}$; all values $\mathrm{p}-\mathrm{NS}$

Table 3 Mean daily dietary intake

\begin{tabular}{lcc}
\hline & $\begin{array}{l}\text { Control group } \\
n=12\end{array}$ & $\begin{array}{l}\text { Resected group } \\
n=12\end{array}$ \\
\hline Fluid $(\mathrm{ml})$ & $1707 \pm 530$ & $2298 \pm 1213$ \\
Total Kcal & $2323 \pm 622$ & $2958 \pm 1057$ \\
Nitrogen $(\mathrm{g})$ & $13 \cdot 3 \pm 4 \cdot 5$ & $17 \cdot 2 \pm 5 \cdot 7$ \\
Fat $(\mathrm{g})$ & $108 \pm 31$ & $125 \pm 47$ \\
$\mathrm{CHo}(\mathrm{g})$ & $251 \pm 81^{*}$ & $346 \pm 134^{*}$ \\
$\mathrm{Na}(\mathrm{mmol})$ & $130 \pm 36$ & $146 \pm 58$ \\
$\mathrm{~K}(\mathrm{mmol})$ & $80 \pm 25$ & $107 \pm 33$ \\
$\mathrm{Ca}(\mathrm{mmol})$ & $24 \pm 8$ & $32 \pm 14$ \\
\hline
\end{tabular}

Values mean $\pm \mathrm{SD} ;{ }^{*} \mathrm{p}<0 \cdot 05$

resected group compared with the control group. Apart from the intake of carbohydrate, however, none of these differences were statistically significant.

\section{BODY COMPOSITION}

Control group versus resected group (Table 4)

Mean body weight was greater in the control group $(68 \cdot 4 \pm 14.3 \mathrm{~kg})$ compared with patients who had undergone resection of the ileum $(61 \cdot 5 \pm 10 \cdot 8 \mathrm{~kg})$. This difference though not statistically significant was largely because of a reduction in total body fat in patients who had undergone a resection of the ileum $(13 \cdot 1 \pm 4.9 \mathrm{~kg})$ compared with the control group $(18 \cdot 0 \pm 7.6 \mathrm{~kg} \mathrm{p}=0 \cdot 06)$. Remarkably similar values for all other measurements of body composition were found for the two groups.

Control group: observed versus predicted values (Table 5)

There was a significant reduction of mean total body nitrogen and total body potassium in the control
Table 4 Body composition results

\begin{tabular}{lcc}
\hline & $\begin{array}{l}\text { Control group } \\
n=12\end{array}$ & $\begin{array}{l}\text { Resected group } \\
n=12\end{array}$ \\
\hline Body wt $(\mathrm{kg})$ & $68 \cdot 4 \pm 14 \cdot 3$ & $61 \cdot 5 \pm 10 \cdot 8$ \\
Total body fat $(\mathrm{kg})$ & $18 \cdot 0 \pm 7 \cdot 6^{*}$ & $13 \cdot 1 \pm 4 \cdot 9^{*}$ \\
Total body nitrogen $(\mathrm{g})$ & $1511 \pm 385$ & $1481 \pm 416$ \\
Total body water (l) & $39 \cdot 7 \pm 8 \cdot 3$ & $40 \cdot 0 \pm 8 \cdot 7$ \\
Total body water diff $(\mathrm{l})$ & $39 \cdot 3 \pm 7 \cdot 7$ & $37 \cdot 5 \pm 7 \cdot 9$ \\
Total body pottasium $(\mathrm{g})$ & $108 \pm 27$ & $106 \pm 32$ \\
Total body sodium $(\mathrm{g})$ & $73 \pm 12$ & $74 \pm 14$ \\
Total body chlorine $(\mathrm{g})$ & $65 \pm 9$ & $65 \pm 12$ \\
Total body calcium $(\mathrm{g})$ & $913 \pm 199$ & $901 \pm 146$ \\
Total body phosphorous $(\mathrm{g})$ & $489 \pm 103$ & $476 \pm 115$ \\
\hline Values mean $\pm \mathrm{SD} ;{ }^{*} \mathrm{p}=0 \cdot 06$ & &
\end{tabular}

Table 5 Body composition: control group: observed versus predicted values

\begin{tabular}{lcc}
\hline & Observed & Predicted \\
\hline Body wt $(\mathrm{kg})$ & $68 \cdot 4 \pm 14 \cdot 3$ & $68 \cdot 5 \pm 8 \cdot 0$ \\
Total body fat $(\mathrm{kg})$ & $18 \cdot 0 \pm 7 \cdot 6$ & $17 \cdot 0 \pm 4 \cdot 9$ \\
Total body nitrogen $(\mathrm{g})$ & $1511 \pm 385^{*}$ & $1671 \pm 377^{*}$ \\
Total body potassium $(\mathrm{g})$ & $108 \pm 27 \dagger$ & $118 \pm 29 \dagger$ \\
Total body water diff $(\mathrm{l})$ & $39 \cdot 3 \pm 7 \cdot 7$ & $37 \cdot 6 \pm 7 \cdot 7$ \\
\hline${ }^{*} \mathrm{p}<0 \cdot 01+\mathrm{p}<0 \cdot 02$ & &
\end{tabular}

group $(1511 \pm 385 \mathrm{~g}$, and $108 \pm 27 \mathrm{~g}$ respectively) compared with predicted normal values $(1671 \pm 377 \mathrm{~g}$; $(\mathrm{p}<0.01)$, and $118 \pm 29 \mathrm{~g}(\mathrm{p}<0.02)$ respectively). The predicted values of weight, total body fat and total body water diff were similar to those of controls.

Resected group: observed versus predicted values (Table 6)

The values for body weight and total body fat were significantly reduced in the patients who had undergone ileal resection $(61.5 \pm 10.8 \mathrm{~kg}$ and $13.1 \pm 4.9 \mathrm{~kg}$ respectively) compared with predicted normal values $(69.2 \pm 8.7 \mathrm{~kg}(\mathrm{p}<0.01)$ and $17.0 \pm 5.6 \mathrm{~kg}$ $(\mathrm{p}<0.02)$ respectively). As with the control group,

Table 6 Body composition: resected group: observed versus predicted values

\begin{tabular}{lcc}
\hline & Resected & Predicted \\
\hline Body wt $(\mathrm{kg})$ & $61 \cdot 5 \pm 10 \cdot 8^{*}$ & $69 \cdot 2 \pm 8 \cdot 7^{*}$ \\
Total body fat $(\mathrm{kg})$ & $13 \cdot 1 \pm 4 \cdot 9 \dagger$ & $17 \cdot 0 \pm 5 \cdot 6 \dagger$ \\
Total body nitrogen $(\mathrm{g})$ & $1481 \pm 416^{*}$ & $1690 \pm 432^{*}$ \\
Total body potassium $(\mathrm{g})$ & $106 \pm 32 \dagger$ & $120 \pm 33 \dagger$ \\
Total body water diff $(\mathrm{l})$ & $37 \cdot 5 \pm 7 \cdot 9$ & $38 \cdot 2 \pm 9 \cdot 0$ \\
\hline
\end{tabular}

${ }^{*} \mathrm{p}<0 \cdot 01 ; \dagger \mathrm{p}<0.02$ 
patients who had undergone a resection of the ileum showed similar statistically significant reductions in total body nitrogen and total body potassium compared with predicted values. The value of total body water diff in the resected group however was similar to that predicted.

\section{Discussion}

This study has shown that proctocolectomy and ileostomy alone without ileal resection does not significantly affect body weight or the body contents of fat or water, but does lead to a reduction in total body nitrogen and total body potassium. It has also shown that a modest resection of the terminal ileum done during the course of proctocolectomy, reduces body weight largely because of a reduction in body fat. Despite quite large ileostomy outputs in this group of patients, however, other measurements of body composition remain unaltered.

While the long term nutritional effects of extensive small bowel resection have been documented, ${ }^{10}$ detailed investigation of body composition has not previously been carried out in groups of ileostomy patients similar to those we studied. It is not possible therefore to compare the results of many of the indices that we measured with those of other investigators. Determinations of body water and electrolytes have, however, been previously documented. Clarke $\mathrm{et}^{\mathrm{al}} \mathrm{l}^{7}$ reported an $11 \%$ reduction in total body water and a $7 \%$ reduction in total exchanageable sodium in ileostomy patients compared with healthy controls, and these findings were later confirmed by Hill et al. ${ }^{8}$ In our study dehydration was not present in the ileostomy patients even when the terminal ileum had been excised, findings which are in agreement with Turnberg et al. ${ }^{9}$ There are several possible explanations for these differences. Firstly Clarke et al and Hill and his colleagues measured total body water using an oral dose of radioactive water, which is less accurate than an intravenous injection used by ourselves and Turnberg et al. ${ }^{9}$ Secondly, in the study by Hill et al the predicted values of total body water were obtained from a control group consisting of only 22 male subjects, who had been measured as part of a previous study. ${ }^{18}$ Another criticism of this study is that nearly half the ileostomy patients had suffered from Crohn's disease, whereas in our study there was only one such patient. As it is now generally accepted that patients with this disease may have impaired intestinal function with abnormalities throughout their gastrointestinal $\operatorname{tract}^{19}{ }^{20}$ the presence of disease in the residual small bowel alone may explain the differences observed. Even if the results of the single patient with Crohn's disease are excluded from our study, the findings remain unchanged.

It is of interest that the present study has shown a significant reduction in total body potassium in ileostomy patients similar to that reported by Turnberg et al. ${ }^{9}$ As the reduction is of the same magnitude for both our groups of ileostomists, this suggests that it is attributable to proctocolectomy alone rather than to ileal resection. Furthermore, accompanying the fall in total body potassium there were comparable reductions in total body nitrogen in both groups of patients, and together these findings indicate a reduction of fat free mass. Exactly why proctocolectomy alone should be associated with this change is unclear. As the colon itself is part of the fat free mass its removal might be expected to reduce total body nitrogen and total body potassium. We have, however, analysed the amounts of nitrogen in the colon, and estimate that the total content in the wall of the colon and rectum accounts for only $15-20 \%$ of the overall change in total body nitrogen that we observed. The reduction in fat free mass suggests therefore that these patients are either malnourished or alternatively have a small but normally constituted fat free mass. This latter explanation could possibly result from either a failure of the fat free mass to develop, if the colitis affected patients at a young age when normal growth and development of lean tissue was occurring. Alternatively it could be because of an irrecoverable erosion of cells constituting the fat free mass if the colitis occurred in later life. Either way even though surgery produces an 'apparent cure' and returns these patients back to health, the fat free mass remains small because of the reduced number of cells and, consequently, it can never attain its predicted size.

If a modest ileal resection is done during the course of proctocolectomy and ileostomy. It is now known that an impairment of ileostomy adaption can occur resulting in increased excretion of water and electrolytes ${ }^{2-5}$ and also fat and nitrogen. ${ }^{6}$ The explanation for these findings is not fully understood, but a combination of factors probably contribute. These include a reduction in absorptive surface ${ }^{21}$ rapid small bowel transit consequent upon resection of the 'ileal brake' mechanism ${ }^{22} 23$ and malabsorption of fat. ${ }^{24}$ In this study we have confirmed the observation of others that ileostomy output is significantly greater in patients who have undergone a resection of the terminal ileum compared with patients who do not undergo a resection. Also, patients in the resected group showed a reduction in weight largely because of the alterations in their total body fat. Although both these reductions failed to reach statistical significance 
when compared with the control group, we feel these are genuine reductions as the differences were highly significant when compared with the predicted values, where age, sex, and height are matched accurately with those of the resected patients. What seems remarkable, however, is that other indices of body composition in patients who had undergone ileal resection compared with their controls, remained unaltered despite the continual malabsorption of nutrients and electrolytes. The explanation for this probably lies in the fact that the patients in the resected group increased their dietary intake of all the major foodstuffs, minerals and fluid. Bingham $e t a l^{25}$ similarly found that the energy and water intake of ileostomy patients was proportional to the length of ileal resection. We believe that it is in this way ileostomy patients who have undergone ileal resection minimise the effect of nutrient malabsorption, and so maintain their nutrition. The reduction in body fat is almost certainly caused by impaired absorption of bile salts and a reduction in the bile salt pool consequent upon a terminal ileal resection. ${ }^{26}$ Thus no matter how much dietary fat is increased, the loss of fat from the stoma is obligatory and cannot be compensated for. The exact length of terminal ileum that needs to be resected in order to deplete the bile salt pool was previously thought to be about $100 \mathrm{~cm}$, but recent work suggests that it may be much shorter ${ }^{27}$ and our results would indirectly support this contention as the median length of terminal ileum resected in patients in the resected group was $54 \mathrm{~cm}$.

In conclusion we have shown that the fat free mass of ileostomy patients with or without terminal ileal resection is reduced compared with that predicted in normal subjects and this could indicate a subclinical state of malnutrition. In neither group, however, have we been able to show any degree of dehydration. Patients who undergo relatively short terminal ileal resections have been shown to lose weight and have reduced fat stores. In view of these findings it would therefore be prudent that close attention is paid to fluid and nutritional therapy in any ileostomy patient who suffers intercurrent illness or requires further surgery. This would be of particular importance for those ileostomy patients who have suffered an ileal resection, no matter how modest.

We are grateful to Professor Johnston for allowing us to study patients under his care. We thank also Mrs Lorna McQuade who typed the manuscript. Mr J C Cooper was funded by a grant from The Yorkshire Regional Health Authority.

\section{References}

1 Gallagher ND, Harrison DD. Skyring AP. Fluid and electrolyte disturbances in patients with longestablished ileostomies. Gut 1962: 3: 219-23.

2 Hill GL, Mair WSJ, Goligher JC. Impairment of ileostomy adaptation in patients after ileal resection. Gut 1974; 15: 982-7.

3 Nuguid TP, Bacon HE, Boutwell J. An investigation of the volume of output and chemical content of ileal discharges following total colectomy and ileostomy. Surg Gynecol Obstet 1961; 113: 733-42.

4 Hill GL. Mair WSJ, Goligher JC. Cause and management of high volume output salt-depleting ileostomy. Br J Surg 1975; 62: 720-6.

5 McNeil NI, Bingham S, Cole TJ, Grant AM, Cummings JH. Diet and health of people with an ileostomy. Pt 2: Ileostomy function and nutritional state. BrJ Nutr 1982; 47: 4(1)7-15.

6 Neal DE, Williams NS, Barker M. King RFGL. The effect of resection of the distal ileum on gastric emptying, and small bowel transit and absorption after proctocolectomy. $\mathrm{Br} J$ Surg 1984; 71: 666-70.

7 Clarke AM, Chirnside A, Hill GL. Pope G, Stewart MK. Chronic dehydration and sodium depletion in patients with established ileostomies. Lancet 1967; 2: 740-3.

8 Hill GL, Goligher JC, Smith AH, Mair WSJ. Long term changes in total body water, total exchangeable sodium and total body potassium, before and after ileostomy. Br J Surg 1975; 62: 524-7.

9 Turberg LA, Morris AI, Hawker PC, Herman KJ, Sheilds RA, Horth CE. Intracellular electrolyte depletion in patients with ileostomies. Gut 1978; 19: 563-8.

10 Bambach CP. Hill GL. Long term nutritional effects of extensive resection of the small intestine. Aust NZJ Surg 1982; 52: 50()-6.

11 Durnin JVGA, Womersley J. Body fat assessed from total body density and its estimation from skinfold thickness: measurements on 481 men and women aged from 16-72 years. Br J Nutr 1974; 32: 77-97.

12 Siri WE. University of California Radiation Laboratory Publication no. 3349. 1959.

13 Hill GL, McCarthy ID, Collins JP, Smith AH. A new method for the rapid measurement of body composition in critically ill surgical patients. Br J Surg 1978; 65: 732-5.

14 Hill GL, King RFGJ, Smith RC, Smith AH, Oxby CR, Sharafi A, Burkinshaw L. Multi-element analysis of the living body by neutron activation analysis - application to critically ill patients receiving intravenous nutrition. Br J Surg 1979; 66: 868-72.

15 Burkinshaw L, McCarthy ID, Oxby C. In: Crook MA, Johnson P. Ed. Multi-element analysis of the living human body by neutron activation analysis. Liquid scintillation counting incorporating whole body counting and radioimmunoassay. Vol 5. London: Heyden, London: 1978.

16 Burkinshaw L, Morgan DB, Silverton NP, Thomas RD. Total body nitrogen and its relation to body 
potassium and fat-free mass in healthy subects. Clin Sci 1981; 61: 457-62.

17 Swinscow TDV. Statistics at square one. 6th ed. London: BMJ, 1976.

18 Hughes D, Williams RE, Smith AH. Clinical studies on whole body potassium contents measured by gammaray spectrometry in health and disease. Clin Sci 1967: 32: 5() $3-9$.

19 Goodman MJ, Skinner JM, Truelove SC. Abnormalities in the apparently normal bowel mucosa in Crohn's disease. Lancet 1976; 1: 275-8.

20 Dunne WT, Cooke WT. Allan RN. Enzymatic and morphometric evidence of Crohn's disease as a diffuse lesion of the gastro-intestinal tract. Gut 1977; 18: 290-4.

21 Hill GL. Ileostomy, surgery, physiology and management. New York: Grunne and Stratton, 1976.

22 Spiller RC, Trotman IF, Higgins BE, et al. The ileal brake - inhibition of jejunal motility after ileal fat perfusion in man. Gut 1984; 25: 365-74.

23 Read NW, McFarlane A. Kinsman RI, et al. Effect of infusion of nutrient solutions into the ileum on gastrointestinal transit and plasma levels of neurotensin and enterglucogon. Gastroenterology. 1984; 86: 274-80.

24 Jeffries GH, Weser E, Sleisenger MH. Malabsorption. Gastroenterology 1969; 56: 777-97.

25 Bingham S. Cummings JH, McNeil NI. Diet and health of people with an ileostomy. Pt 1: Dietary assessment. Br J Nutr 1982: 47: 399-406.

26 Heuman R, Sjodahl R, Tobiasson C, Tagesson C. Postprandial serum bile acids in resected and nonresected patients with Crohn's disease. Scand J Gastroenterology 1982; 17: 137-40.

27 Cooper G. Abel BJ, Hutchinson AG, MacKay C. What length of terminal ileum is required for bile salt absorption? [Abstract]. Gut 1982; 23: A892-3. 